\title{
Effects of compressor speed and electronic expansion valve opening on the performance of R410a water chiller system
}

\author{
Ahmed H. Al-Hassani ${ }^{1}$ | Alaa R. Al-Badri ${ }^{1}$
}

\author{
Affiliations \\ ${ }^{1}$ Mechanical Engineering \\ Department, Wasit University, \\ Wasit, Iraq \\ Correspondence \\ Ahmed H. Al-Hassani, \\ Mechanical Engineering \\ Department, Wasit University, \\ Wasit, Iraq \\ Email: ahasany@uowasit.edu.iq \\ Received \\ 22-February-2020 \\ Revised \\ 01- April-2020 \\ Accepted \\ 22- April-2020 \\ doi: $x x x x x x x x x x$
}

\begin{abstract}
Refrigeration and air conditioning systems consume high rates of electrical energy of the total global power consumption. The major part of this energy is used by compressor which is the main equipment in vapor compression refrigeration systems. In this study, the performance of a variable speed chilled water refrigeration system with electronic expansion valve (EEV) is experimentally investigated. The system is composed of variable speed rotary compressor, water cooled condenser, electronic expansion valve, and evaporator with refrigerant R410a for one tone cooling capacity. The results showed that the EEV opening was related to the compressor speed at limits of refrigerant subcool and system stability to achieve better performance. Refrigerant superheats increased with closing the EEV at constant compressor speed. Moreover, the degree of superheat was inversely proportional to the compressor speed at constant EEV opening. The coefficient of performance (COP) was improved by about 2.2 to $4.0 \%$ by controlling the EEV at constant compressor speed. Increasing compressor speed from 1200 to $3600 \mathrm{rpm}$ resulted in decreasing system COP from 5.2 to 2.35 due to the increase of the power consumed by compressor.
\end{abstract}

Keywords: Variable speed compressor, water chiller, EEV, degree of superheat, R410a.

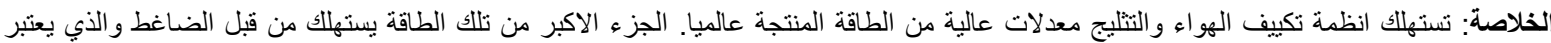

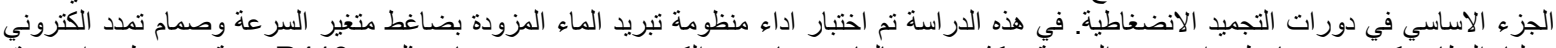

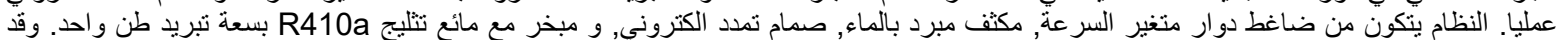

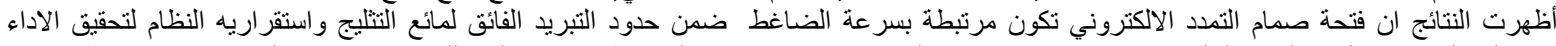

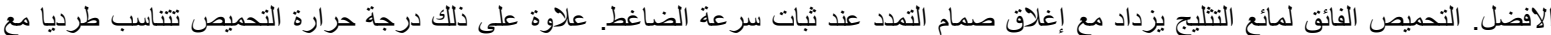

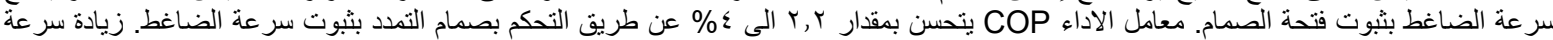

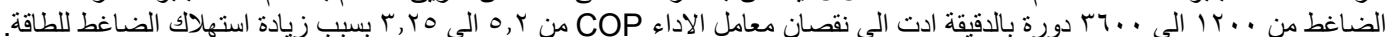

\section{INTRODUCTION}

Refrigeration systems consume about $40 \%$ from the total power [1]. With a new technology of variable speed compressor, energy saving is about 30\% [2]. Increasing variable speed refrigeration systems efficiency is by using electronic expansion valve and controllers [3]. Cohen et al. [4] improved the air conditioning system by using a variable speed compressor. Energy saving was only in the spring and autumn seasons because of partial load where the compressor becomes more efficient at low speeds due to the decrease in both mechanical frictional losses and also cycle pressure compression ratio. Energy saving from 28 to 35\% was achieved using thermostatic expansion valve instead of capillary tube because of low torque required at compressor start up and few On/Off cycles at those seasons. Shimma et al. [5] used a variable frequency drive to control compressor speed with air conditioning $(\mathrm{A} / \mathrm{C})$ system. This technique improved the system COP by about 20 to $40 \%$ 
depending on the controlling method at low demand conditions. At low compressor speed, the thermal efficiency of both evaporator and condenser was increased and also the power consumption was decreased. The effect of compressor speed variation and EEV opening on the power consumption and refrigeration effect in cooling chiller systems was numerically investigated by Koury et al. [6]. The numerical simulation results showed that when compressor speed increased, the COP decreased because of the higher power consumption in spite of the increase in refrigeration effect. Increasing EEV opening increases the COP too with a limit of safety for compressor operation from refrigerant drops. The improvement of the inverter systems was by using modified equipment and intelligent controllers. Chang et al. [7] presented a refrigerator-freezer with a variable brushless direct current motor reciprocating compressor and a microcontroller which depended on the temperature difference as a function to the change in compressor motor frequency. The results showed that energy-saving in winter and summer were 34 and $22 \%$, respectively due to differences in thermal loads. The effects of operating conditions on system power consumption were investigated by Aprea et al. [8] for cooling and heating modes. They compared constant frequency reciprocating compressor and variable frequency scroll compressor with different temperature sets for evaporator and condenser at a variable water mass flow rate for a constant thermal load. The experimental results showed higher energy consumption by using constant speed compressor at all operating conditions and the effect of decreasing evaporation temperature increased power consumption and also at increasing condenser temperature. The amount of refrigerant flow depends on compressor speed and valve opening. Lago et al. [9] studied the effect of compressor speed on EEV opening for $\mathrm{A} / \mathrm{C}$ system to achieve maximum COP. The experimental results showed that at each compressor speed, there was an EEV opening with maximum COP for refrigeration systems with a variable speed compressor. Heating and ventilation Air condition systems are designed at maximum load conditions, but when the system runs at partial loads, the conventional refrigeration systems becomes at On/Off operation which results in more power consumption. Schibuola et.al [1] studied A/C system for two rooms with different loads along one year at cooling and heating modes. The experimental results showed that energy saving can be increased by $38.9 \%$ using a variable speed driver for both the compressor and fans compared to single speed equipment. Tu et al. [10] developed a dynamic model to control a variable refrigerant flow system including variable speed compressor, EEV and sub-cooler. The optimum energy efficiency ratio was at narrow EEV opening under partload condition. Narrow EEV opening affected the amount of refrigerant subcool at a certain compressor speed which led to increasing refrigeration capacity.

The aim of this study is to experimentally investigate the effects of compressor speed and valve opening on the performance and characteristics of a water chiller refrigeration system. The study takes into consideration the degree of superheat, refrigerant mass flow rate, condenser pressure, evaporator pressure, subcool, refrigeration rate and power consumption.

\section{EXPERIMENTAL RIG}

The experimental rig was a model of refrigeration chiller system with R410a as a refrigerant equipped with a variable speed twin rotary compressor and EEV for one-ton cooling capacity. Two shell and coil copper tube heat exchangers were used as evaporator and condenser. Coil copper tube diameter was $9.5 \mathrm{~mm}$ with tube lengths 6.5 and $9.5 \mathrm{~m}$ for evaporator and condenser, respectively. Four pressure and temperature sensors at input and output of each exchanger with direct contact to refrigerant were connected. The pressure sensors have a range of $0-40$ bar with total error of \pm 0.3 bar and the temperature sensors were commercial NTC-10K $\Omega$ type with total error $\pm 0.3{ }^{\circ} \mathrm{C}$, which was determined by calibration process against precise sensor. The refrigerant flow rate was measured by a refrigerant flow meter which was suitable for refrigerant R410a with a flow range of $0.2-2 \mathrm{~L} / \mathrm{min}$ and error of $\pm 0.354 \mathrm{~mL} / \mathrm{s}$. Compressor speed was regulated from 1200 to $3600 \mathrm{rpm}$ by variable frequency drive for brushless direct current motors which is controlled by a $0-5 \mathrm{v}$ signal with error $\pm 0.5 \%$. Data acquisition with LabVIEW was used to record sensors data and also to control compressor speed and EEV opening. Evaporator and condenser water flow rates and temperatures at input and output were into consideration. Figure 1 shows a sketch diagram of the experimental rig.

The experiments were done in spring as the apparatus was well isolated. The degree of superheat value was calculated based on the difference between evaporator outlet refrigerant temperatures $\left(T_{e, r, o}\right)$ and refrigerant saturation temperature at evaporator outlet pressure $\left(\mathrm{T}_{\mathrm{e}, \mathrm{r}, \mathrm{s}}\right)[11]$.

$$
D S=T_{e, r, o}-T_{e, r, S}
$$


The coefficient of performance (COP) was calculated depending on the output cooling rate from the evaporator (Qe) which depends on the water temperature difference from Eq. (2).

$$
C O P=\frac{Q_{e}}{W}=\frac{\dot{m_{w}} * C_{p, w} *\left(T_{e, w, i}-T_{e, w, o}\right)}{W}
$$

Where $(\mathrm{W})$ is the compressor power, $\left(\mathrm{m}_{\mathrm{w}}\right)$ is the water flow rate, $\left(\mathrm{C}_{\mathrm{w}}\right)$ is the specific heat capacity of water which equals $4.19 \mathrm{~kJ} / \mathrm{kg} . \mathrm{K}$, and $\mathrm{T}_{\mathrm{e}, \mathrm{w}, \mathrm{i}}, \mathrm{T}_{\mathrm{e}, \mathrm{w}, \mathrm{o}}$ are the evaporator inlet and outlet water temperature respectively.

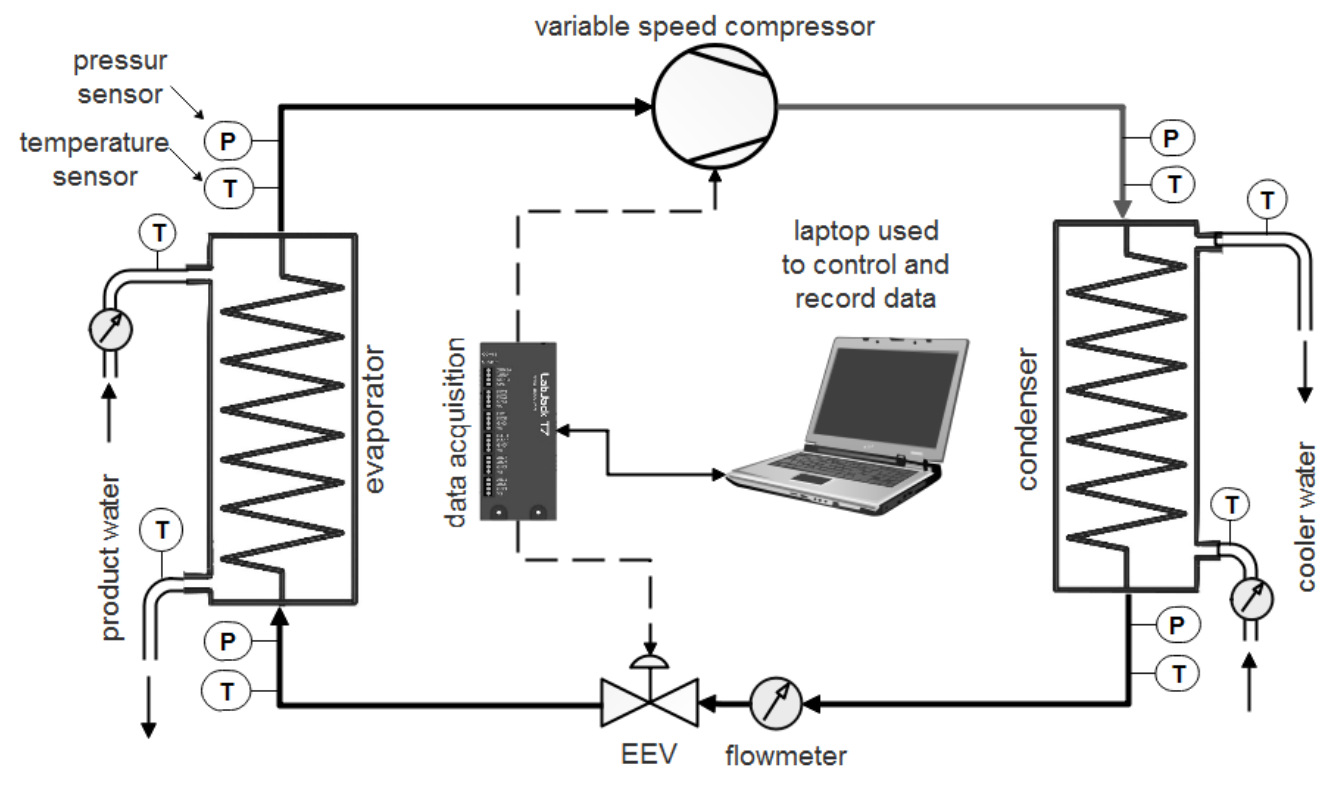

Figure 1 Schematic of the apparatus

The uncertainty in the coefficient of performance $\left(\mathrm{U}_{\mathrm{COP}}\right)$ was evaluated depending on the method of multisamples uncertainty analysis [12]. This method depends on the fixed and random error determination for each measured parameter as appeared in Eq. (3).

$$
U_{C O P}=\left[\sum_{i=1}^{n}\left(\frac{\partial C O P}{\partial x_{i}} \delta x_{i, f}\right)^{2}+\sum_{i=1}^{n}\left(\frac{\partial C O P}{\partial x_{i}} \delta x_{i, r}\right)^{2}\right]^{1 / 2}
$$

Where $\left(x_{i, f}\right)$ and $\left(x_{i, r}\right)$ is the fixed and random errors of the measurand $\left(x_{i}\right)$ respectively, and (n) is the number of measurands. The COP is a function of water flow rate, evaporator inlet, and outlet water temperatures, and power see Eq. (2). The random error was calculated for each measurand by the following equation [12]:

$$
\delta x_{i, r}=\frac{t * \sigma_{i}}{\sqrt{N}}
$$

Where $\left(\sigma_{i}\right)$ is the samples' standard deviation, $(\mathrm{t})$ was chosen to be 2 with a confidence level of $95 \%$ which corresponds to the degree of freedom $(N-1)$, and $(N)$ is the number of samples. The fixed error of the temperature sensors, water flow meter, and power meter are $1 \%, 2 \%$, and $0.5 \%$ respectively according to the manufacturer's data. The total error in measurements was $\pm 0.3^{\circ} \mathrm{C}, \pm 1.8 \mathrm{~mL} / \mathrm{s}$, and $6.5 \mathrm{w}$ under steady state conditions. The uncertainty limits of the COP were 4.5 to $6.8 \%$. 


\section{RESULTS AND DISCUSSIONS}

Compressor speed has an impact on refrigerant flow rate in the cycle; consequently, it would affect the refrigeration capacity. EEV is also working as the main part of variable speed refrigeration systems to regulate degree of refrigerant superheat at desired values and to maintain pressure ratio at optimum working levels [10]. System performance under manual operation was examined to determine the effect of compressor speed and valve opening at constant inlet water temperatures to the evaporator and condenser 17 and $29{ }^{\circ} \mathrm{C}$, respectively. Closing EEV led to increasing condenser pressures that achieved refrigerant subcool, more closing resulted in hunting which can be defined as "the phenomena of the oscillation of certain system operating parameters such as the degree of refrigerant superheat, refrigerant mass flow rate and evaporating pressure" [13]. The Optimum operation of the variable speed refrigeration system depends on the amount of refrigerant superheat outlet from evaporator. The degree of superheat affects both refrigerants' subcooling and systems' stability [14]. Refrigerant subcooling value was calculated from the equation:

$$
\text { subcool }=T_{c, r, o}-T_{c, r, s}
$$

Where $\left(T_{c, r, o}\right)$ is the condenser refrigerant outlet temperature and $\left(T_{c, r, s}\right)$ is the saturation refrigerant temperature at condenser outlet refrigerant pressure.

The collected data at steady state operation was drawn as figures to show the effects of compressor speed and EEV on the system performance while the other parameters were constant. Optimum operating conditions were selected based on achieving refrigerant subcool state outlet from condenser and avoid system hunting [15]. Figure 2 shows the effect of EEV opening on the refrigerant flow rate at each compressor speed. The refrigerant mass flow rate was directly proportioned to the compressor speed and also to EEV opening. Increasing compressor speed increases revolutions per minute that affect refrigerant flow as appeared in the following equation [16]:

$$
\dot{m_{r}}=\eta_{v} * N * V_{d} * \rho_{v}
$$

Where $\left(m_{r}\right)$ is the refrigerant flow rate, $\left(\eta_{v}\right)$ compressor volumetric efficiency, $(N)$ compressor speed, $\left(V_{d}\right)$ compressor displacement volume and $\left(\rho_{v}\right)$ refrigerant vapor density at evaporator outlet.

Figure 3 shows the effect of EEV opening on the evaporator pressure $\left(\mathrm{P}_{e}\right)$ which increases with the increase in EEV opening. In addition, the evaporator pressure decreases with increasing compressor speed due to starving of the evaporator tube (a small quantity of refrigerant). Figure 4 shows the effects of EEV opening on the condenser pressure $\left(\mathrm{P}_{\mathrm{c}}\right)$. The condenser pressure increases with increasing compressor speed at constant EEV opening because of trappings the refrigerant charge in the condenser pipes. In addition, condenser pressure decreases with increasing EEV opening at constant compressor speed due to allow refrigerant charge to cross into the evaporator. Figure 5 shows the effect of the EEV opening on the refrigerant superheat which increases with closing EEV at constant compressor speed and decreases with increasing compressor speed at constant EEV opening. EEV closing leads to decrease refrigerant flow to the evaporator which leads to increasing refrigerant superheat. Refrigerant flow increases with increasing compressor speed that results in decreases superheat. The amount of refrigerant subcooling is directly proportioned to compressor speed. At a constant compressor speed, EEV closing leads to increase subcool due to the increase of $P_{c}$ as shown in Figure 6 . Increasing condensing pressure leads to increase refrigerant saturation temperature that affects the amount of heat transfer to water due to refrigerant saturation pressure enthalpy behavior. 


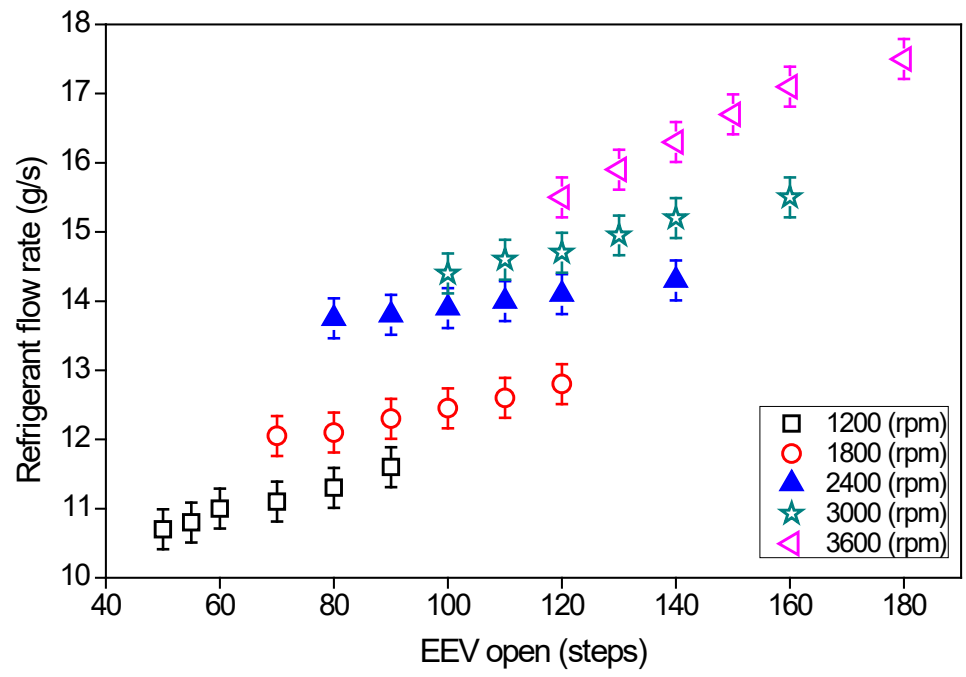

Figure 2 EEV opening size versus refrigerant mass flow rate with five different compressor speeds

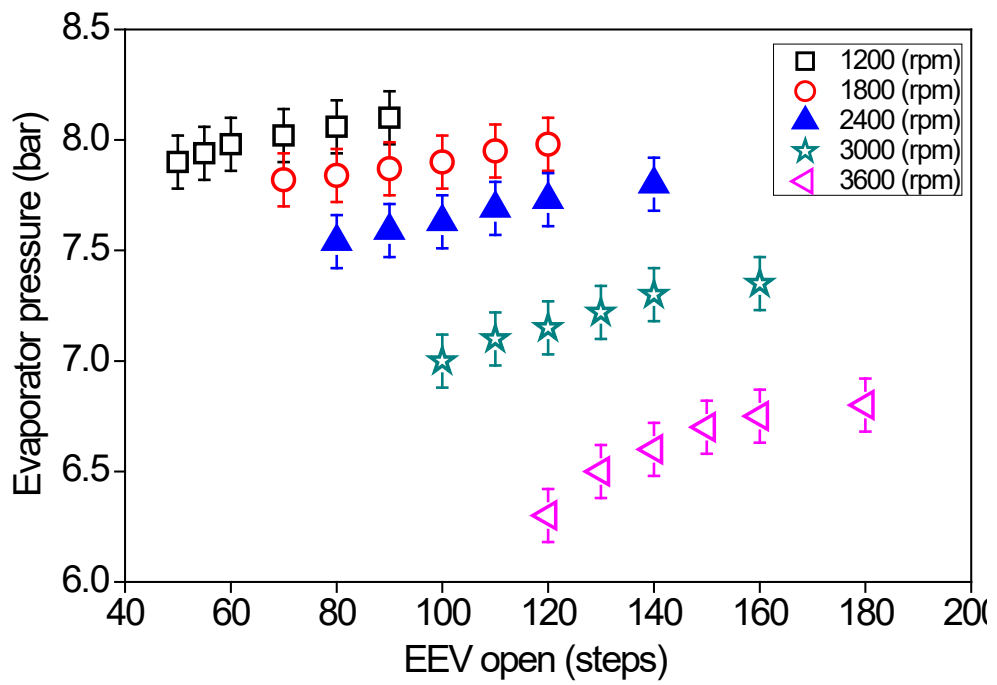

Figure 3 EEV opening size versus evaporator pressure with different compressor speeds

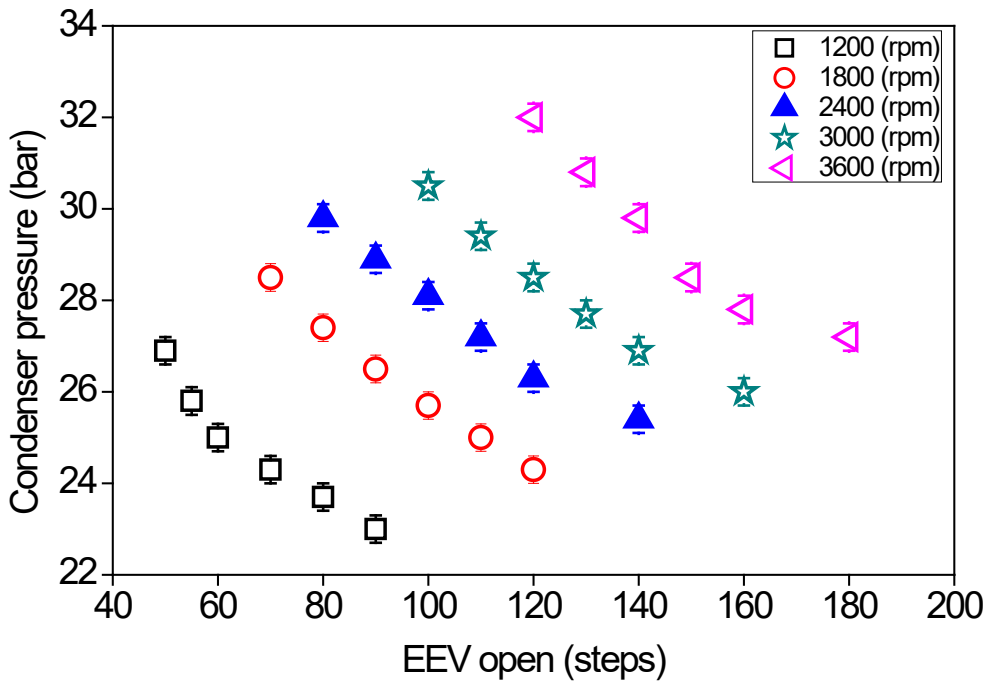

Figure 4 EEV opening size versus condenser pressure with different compressor speeds 


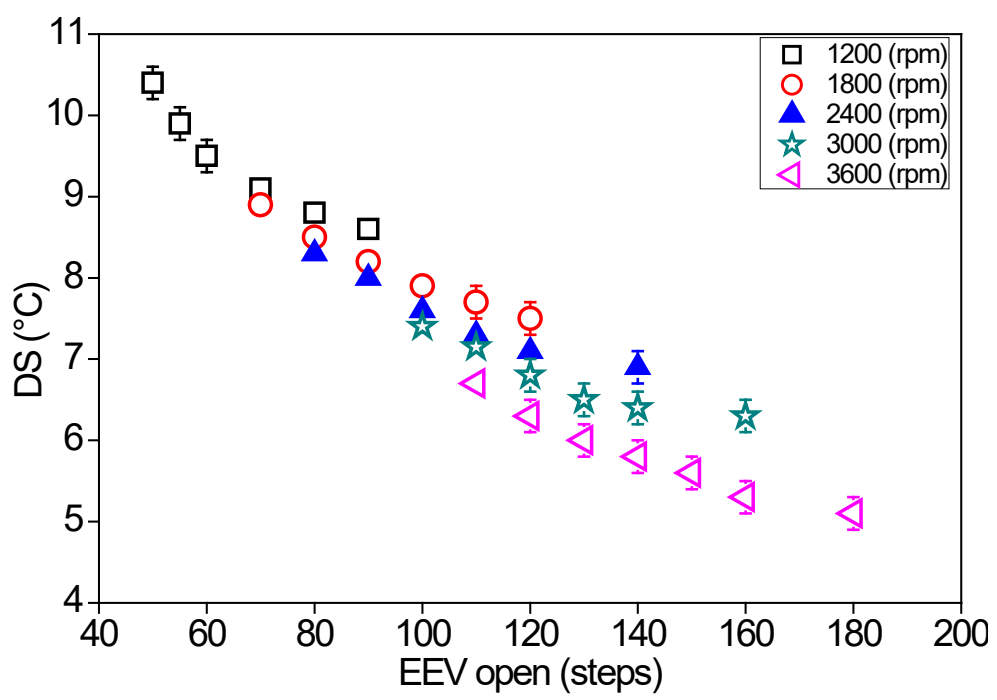

Figure 5 EEV opening size versus the refrigerant DS at different compressor speeds

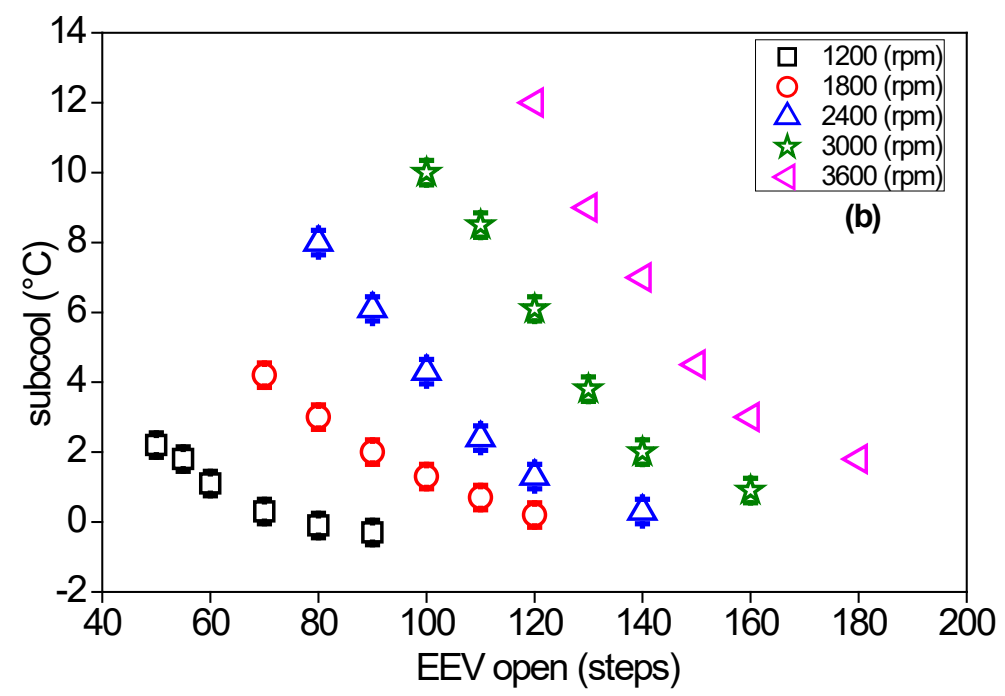

Figure 6 EEV opening size versus refrigerant subcooling at different compressor speeds

Compressor power consumption is directly proportional to compressor speed and it is also affected by EEV opening. Closing EEV leads to increase pressure ratio that results in increased power consumption at constant compressor speed as shown in Figure 7. Increasing compressor speed increases the refrigeration rate $\left(\mathrm{Q}_{\mathrm{e}}\right)$ due to increasing refrigerant flow and at constant a EEV opening leads to increasing condenser pressure that affects refrigerant subcooling. At a constant compressor speed closing, EEV leads also to increase in $\mathrm{Q}_{\mathrm{e}}$ due to the increased pressure ratio that affects refrigerant subcool. More closing, EEV decreases refrigerant flow to the evaporator as shown in Figure 8. EEV opening affects product cold water temperature $\left(\mathrm{T}_{\mathrm{e}, \mathrm{w}, \mathrm{o}}\right)$, at constant compressor speed, decreasing EEV opening leads to decrease evaporation temperature that is reflected on the $\mathrm{T}_{\mathrm{e}, \mathrm{w}, \mathrm{o}}$ as shown in Figure 9. The compressor speed affects $\mathrm{T}_{\mathrm{e}, \mathrm{w}, \mathrm{o}}$ and the DS, and also the EEV opening affects the DS and $\mathrm{T}_{\mathrm{e}, \mathrm{w}, \mathrm{o}}$. This coupling between the compressor and EEV affects the working stability of the refrigeration system [10].

Figure 10 shows the effect of the EEV opening on the coefficient of performance (COP) of the experimental system. The COP increases at low compressor speed due to decreasing of compressor frictional losses and also pressure ratio between $\mathrm{P}_{c}$ and $\mathrm{P}_{e}$ which results in decrease of compressor power consumption. The COP increases by decreasing EEV opening at each speed due to the increase of refrigerant liquid subcooling outlet from the condenser. More closing, the EEV led to a decrease in the COP value due to decreasing in refrigerant flow to the evaporator. 


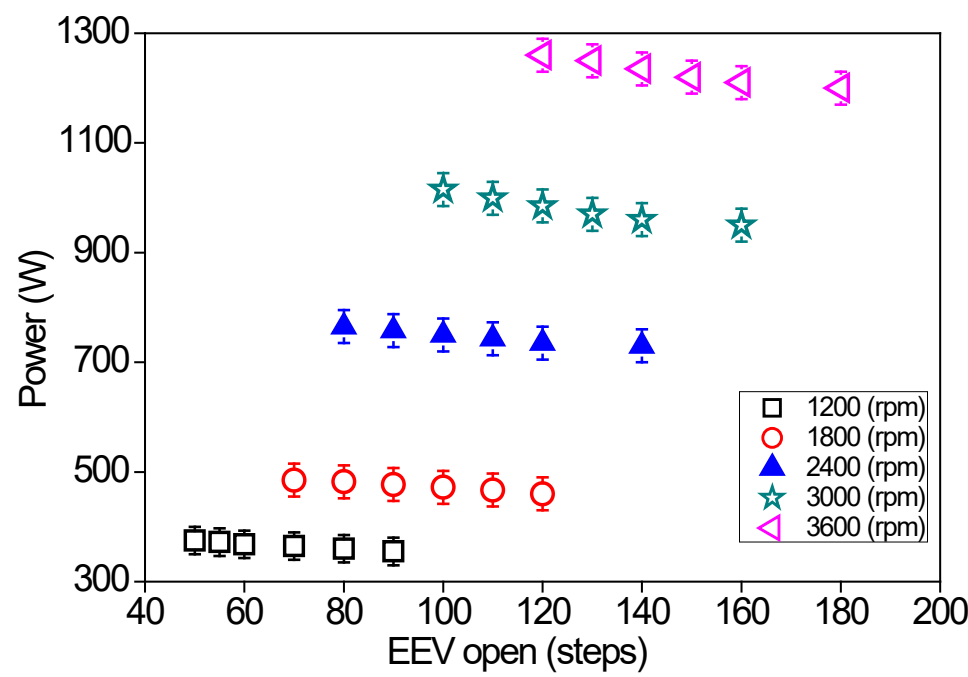

Figure 7 Power consumption versus EEV opening with variable compressor speeds

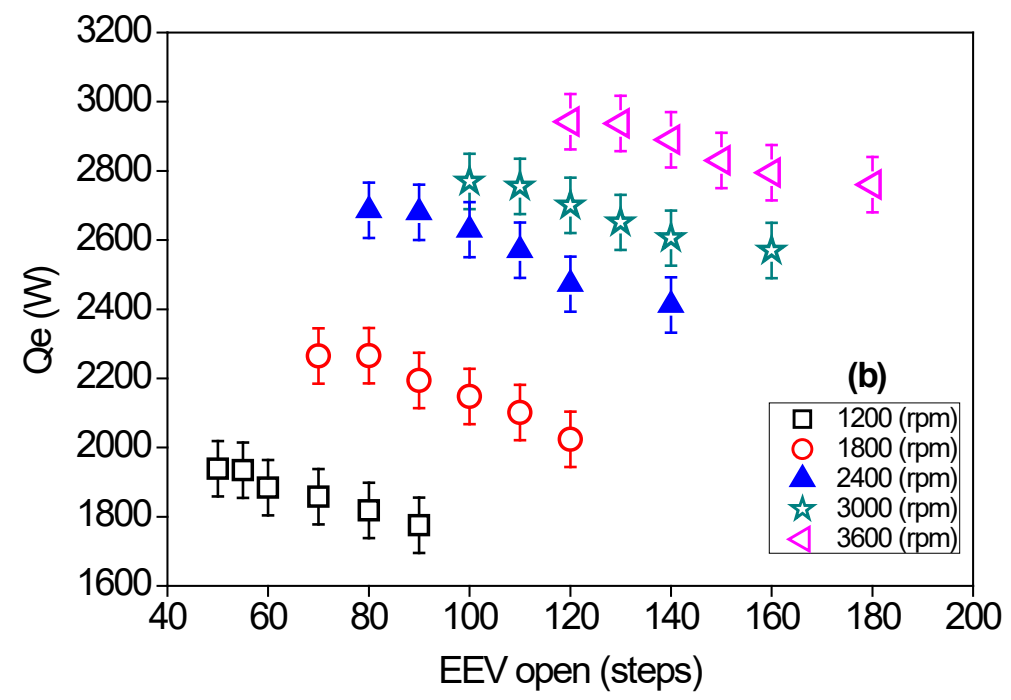

Figure 8 Refrigeration capacity versus EEV opening with variable compressor speeds

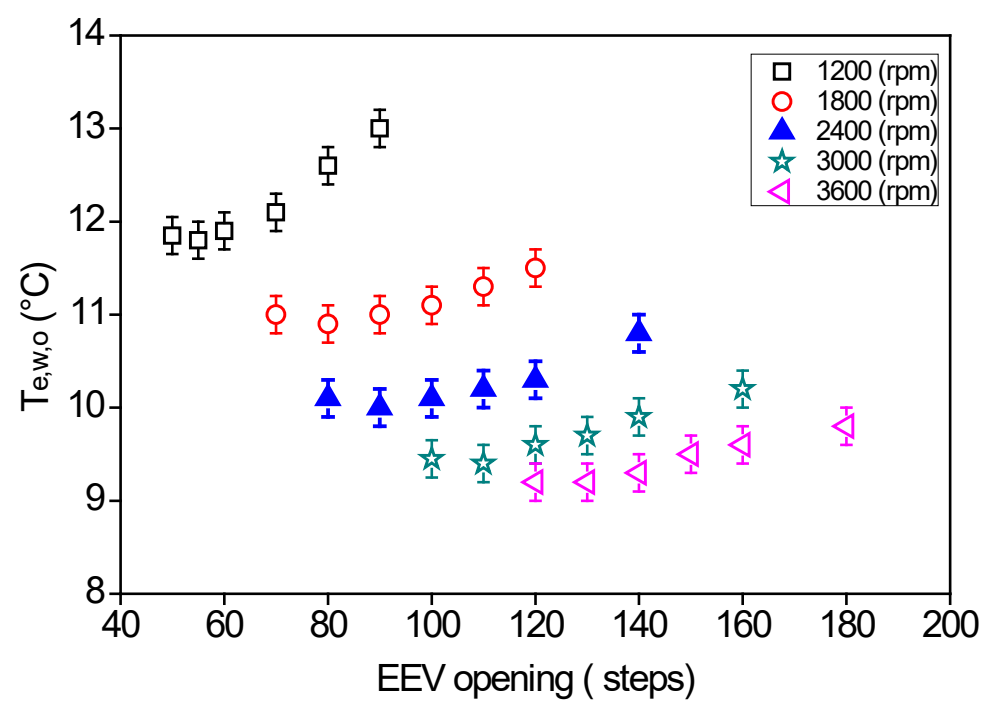

Figure 9 Effect of the EEV opening on the $\left(\mathrm{T}_{\mathrm{e}, \mathrm{w}, \mathrm{o}}\right)$ at each compressor speed 


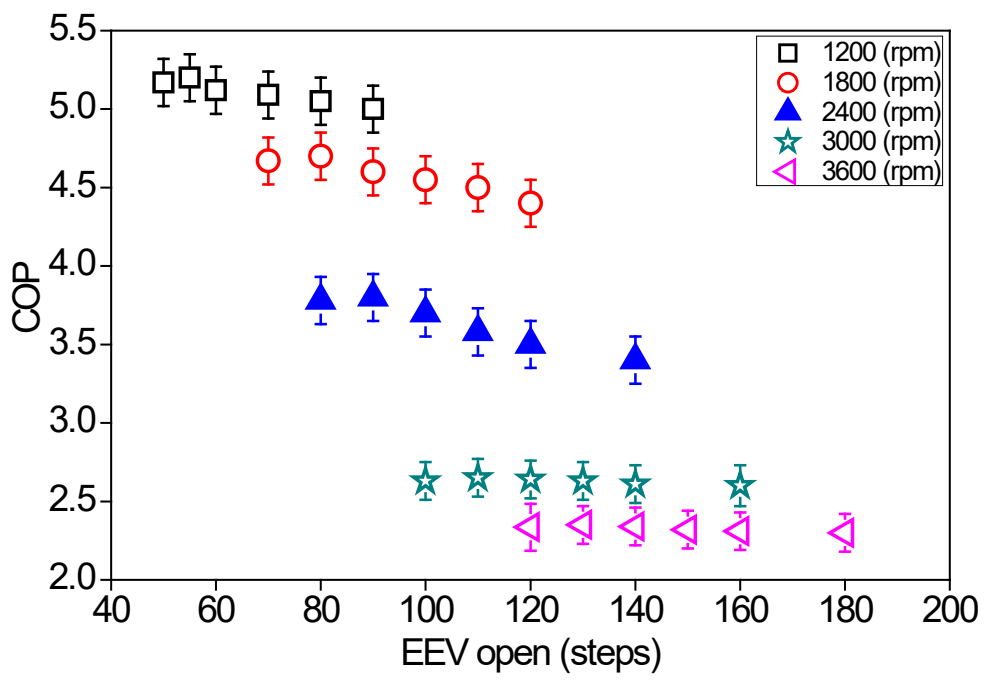

Figure 10 EEV opening size versus coefficient of performance with variable compressor speeds

\section{CONCLUSIONS}

The performance and characteristics of a water chiller refrigeration system were experimentally investigated. The influence of compressor speed and EEV opening on system operation were taken into account. The results showed that the evaporator pressure decreases from 7.94 to 6.5 bar with increasing the compressor speed from 1200 to $3600 \mathrm{rpm}$, respectively. Unlike the evaporator pressure, the condenser pressure raises from 25.8 to 30.9 bar with an increase in the compressor speed. The degree of superheat increased about $15 \%$ with controlling the EEV at each constant compressor speed. Moreover, the degree of superheat decreased from 9.9 to $6{ }^{\circ} \mathrm{C}$ with increasing the compressor speed. The coefficient of performance (COP) was improved from 2.35 to 5.2 with low compressor speed and small EEV opening. For optimum operation conditions, the degree of superheat was related to compressor speed for variable speed compressor with EEV systems.

\section{NOMENCLATURES}

\begin{tabular}{|c|c|c|c|}
\hline \multicolumn{2}{|c|}{ Nomenclatures } & \multicolumn{2}{c|}{ Greek symbols } \\
\hline $\mathrm{A} / \mathrm{C}$ & Air Condition system. & $\eta_{v}$ & Volumetric efficiency \\
\hline$C_{w}$ & Water specific heat, $\mathrm{J} / \mathrm{kg} .{ }^{\circ} \mathrm{C}$ & $\rho$ & Density, $\mathrm{kg} / \mathrm{m}^{3}$ \\
\hline $\mathrm{DS}$ & Degree of Superheat, ${ }^{\circ} \mathrm{C}$ & $\sigma$ & Standard deviation \\
\hline $\mathrm{EEV}$ & Electronic Expansion Valve. & \multicolumn{2}{|c|}{} \\
\hline$\dot{\mathrm{m}}$ & Mass flow rate, $\mathrm{kg} / \mathrm{s}$ & $c$ & Subscripts \\
\hline$N$ & Compressor speed, $\mathrm{rpm}$ & $e$ & Condenser \\
\hline $\mathrm{P}$ & Pressure, bar & $i$ & Evaporator \\
\hline $\mathrm{T}$ & Temperature, ${ }^{\circ} \mathrm{C}$ & $o$ & Inlet \\
\hline $\mathrm{U}$ & Uncertainty & $r$ & Outlet \\
\hline$V_{d}$ & Displacemigerant \\
\hline $\mathrm{W}$ & Powert Volume, $\mathrm{m}^{3} / \mathrm{rev}$ & $s$ & Saturation state \\
\hline$Q$ & Heat transfer rate, $\mathrm{W}$ & $w$ & Water \\
\hline
\end{tabular}

\section{REFERENCES}

1. Schibuola L, Scarpa M, \& Tambani C, (2018). Variable speed drive (VSD) technology applied to HVAC systems for energy saving: an experimental investigation. Energy Procedia, 148: 806-813. 
2. Khatri R, \& Joshi A, (2017). Energy performance comparison of inverter based variable refrigerant flow unitary AC with constant volume unitary AC. Energy Procedia, 109: 18-26.

3. Binneberg P, Kraus E, \& Quack H, (2002). Reduction in power consumption of household refrigerators by using variable speed compressors., in: International Refrigeration and Air Conditioning Conference, Purdue University, Purdue.

4. Cohen R, Hamilton J, \& Pearson T, (1974). Possible energy conservation through use of variable capacity compressors., in: International Compressor Engineering Conference, Purdue University, Purdue.

5. Shimma Y, Tateuchi T, \& Suglura H, (1985). Inverter control systems in the residential heat pump air conditioner. ASHRAE Trans.;(United States), 91(CONF-850606-).

6. Koury R, Machado L, \& Ismail K, (2001). Numerical simulation of a variable speed refrigeration system. International journal of refrigeration, 24(2), 192-200.

7. Chang W, Liu D, Chen G, \& Wu Y, (2004). The Components and Control Methods for Implementation of Inverter-Controlled Refrigerators/Freezers., in: International Refrigeration and Air Conditioning Conference, Purdue University, Purdue.

8. Aprea C, Mastrullo R, \& Renno C, (2006). Experimental analysis of the scroll compressor performances varying its speed. Applied thermal engineering, 26(10), 983-992.

9. Taynara L, Claudia N, Luiz F, (2016). Experimental investigation on variable speed compressor with an electronic expansion valve in a refrigeration system, in: 16th Brazilian Congress of Thermal Sciences and Engineering, Brazil.

10. Tu Q, Zhang L, Cai W, Guo X, Yuan X, Deng C, \& Zhang J, (2018). Control strategy of compressor and sub-cooler in variable refrigerant flow air conditioning system for high EER and comfortable indoor environment. Applied Thermal Engineering, 141, 215-225.

11. Pršić D, Vičovac A, \& Stojanović V, (2016). The Static Characteristic of the Evaporator Superheat Control Loop. In Proceedings of the VIII XIII International SAUM Conference on Systems, Automatic Control and Measurements (pp. 242-245).

12. Moffat, R, (1988). Describing the uncertainties in experimental results. Experimental thermal and fluid science, 1(1), 3-17.

13. Xia Y, \& Deng S, (2016). A Modeling Study on the Operational Stability of a Variable Speed Direct Expansion Air Conditioning System, in: International Refrigeration and Air Conditioning Conference.

14. Kuk F, \& Hau O, (2017). Compression speed and cognition: A variable speed compressor for all. Hearing Review, 24(3), 40-48.

15. Xia Y, Ding Q, Jiang Z, Deng S, \& Song M, (2019). Development of a superheat controller for mitigating hunting in a direct expansion air conditioning system. Energy Procedia, 158, 2085-2091.

16. Lei Z, \& Zaheeruddin M, (2005). Dynamic simulation and analysis of a water chiller refrigeration system. Applied Thermal Engineering, 25(14-15), 2258-2271. 